\title{
Study on the Simulation Technique for Urban Electromagnetic Environment Supported by GIS
}

\author{
Yanming CHEN, Jie LIU, Jiechen WANG \\ Geographic Information Science Department, Nanjing University, Nanjing, 210093, China
}

\begin{abstract}
Electromagnetic radiation environment is one of the important environmental factors. In resent 20 years, the applications of electromagnetic technology became more and more popular. However, electromagnetic environment makes some negative impacts on the surrounding environments and human health, and Environmental Management and Research Department pay a lot attention to it. It will make a great significance if we study of the simulation technique for urban electromagnetic environment which supported by GIS. This paper presents some key technologies of the electromagnetic environment simulation, including terrain rendering, city building modeling and volume data superposition, basically realize the visualization of volume data (electromagnetic fields) based on city building model and real time mapping of virtual scene data.
\end{abstract}

Keywords: electromagnetic radiation environment; visualization; geographical information system

\section{GIS 支援下城市電磁環境仿真技術}

\author{
陳炎明，劉 傑，王結臣 \\ 南京大學＼cjkstart地理資訊科學系，江蘇 南京，210093
}

\begin{abstract}
摘 要: 城市電磁輻射環境是一項重要的環境要素, 近 20 年以來, 電磁技術的發展與應用日益廣泛, 對周 圍環境及人體健康等影響也日益嚴重, 環境保護管理部門以及科研部門等電磁環境的檢測予以高度的重 視。基於 GIS 技術的城市電磁環境仿真, 對此具有重要的意義。本文研究了 GIS 技術支援下, 電磁環境仿 真的若干關鍵技術, 包括地形渲染、城市建築物建模和體資料疊加渲染等, 基本實現了城市建築群模型下 的標量場體資料(電磁場資料)的視覺化及虛擬場景中體資料(電磁場資料)的即時繪製。
\end{abstract}

關鍵字：電磁輻射環境；視覺化；地理資訊系統

\section{1. 前 言}

隨著科技的發展，越來越多的電磁輻射設施進入 人類生活和生產的各個領域, 電磁設施在給人類帶來 便利的同時, 也把人們帶入一個複雜與惡化的電磁環 境中。當環境中電磁輻射強度增加到一定程度時, 生 物體健康將受到有害影響, 電子設備也易受到干擾 [1]。為此, 研究電磁空間分佈特徵有助於瞭解電磁 污染程度和電磁輻射分佈特性, 及人們在電磁環境下 的暴露狀況, 以便防止電磁污染, 保證電磁相容, 保 護人體健康，為城市管理提供科學依據。
空間實體的位置、拓撲關係和幾何特徵是地理資 訊系統所獨有的 [2], GIS 可以有效地用於電磁空間分 佈研究與管理的應用。目前, GIS 應用於該領域已有 嘗試, 然而這些研究仍只是起步階段, 雖有一些經驗 可借鑒，但卻存在 GIS 與電磁領域結合仍不深入的問 題。鑒於此，本文針對該問題進行嘗試性研究。考慮 到在電磁學等領域, 在電磁輻射傳輸模型等方面已有 成果, 本文重點不探討這些方面; 而是重點研究 GIS 應用與電磁仿真的主要技術, 即空間資料獲取與處 理、地形視覺化、城市空間場景視覺化以及標量資料 場視覺化等。 


\section{2. 技術路線}

城市電磁輻射環境仿真的目標是在三維城市空間 中類比、表現出電磁場變數 (如場強) 強弱的空間分 佈，以便管理部門進行相關決策。其中的關鍵問題 是: 空間資料的獲取、地形場景視覺化、城市空間建 築群建模以及電磁資料的標量場視覺化方法。據此, 我們設計了如下技術路線如（圖 1 所示）。

首先, 獲取所需空間資料並對其進行處理。其次, 在空間資料獲取與處理的基礎上, 利用相關演算法實 現地形渲染、城市建築物建模以及利用類比產生的電 磁場資料進行科學資料的渲染。最後, 對先前所做 的模型和渲染效果進行匹配疊置, 完成城市建築群 模型下的標量場資料（電磁場）的視覺化, 實現場 景輸出。它將有助於其他領域的研究人員在城市模 型下對科學資料進行圖形化的觀察, 從而更好地展 開研究。

\section{3. 研究區及資料處理}

本研究中我們以南京市珠江路為中心建立試驗 區, 該區域位於城市的中心地區, 人口稠密, 交通繁 忙。整個區域北面沿北京西路-北京東路線, 西面沿 上海路線, 向南到漢中路, 向東到進香河路, 周長約 5.5 公里, 面積約 1.7 平方公里。在這一區域內進行城 市建築物的建模和環境要素的分析, 具有一定的代表 性和研究意義。

研究中所用資料主要有: IKONOS 彩色合成影像 ( 圖 2 ) 和城市 CAD 地形圖（圖 3 )。資料處理中我 們主要完成資料格式轉換、圖像糾正、坐標系匹配等 資料預處理, 以及為進行視覺化而進行的資料再處 理。後者包含高程資料插值生成地形格網, 建築物資 料通過人工修正方式建立平面結構圖, 以及利用數值 方法求解關於場強分佈的泊松方程來類比產生電磁場

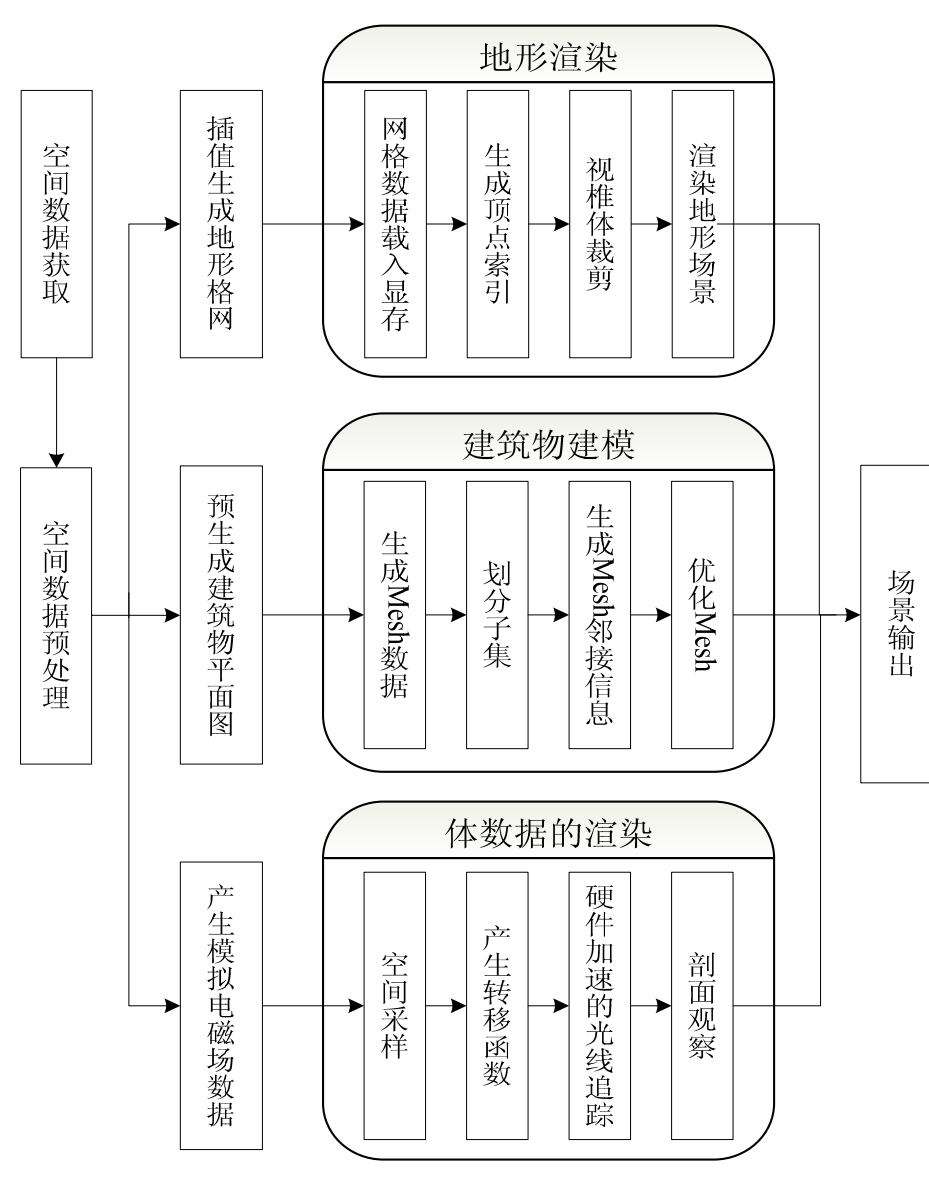

圖 1. 技術路線圖

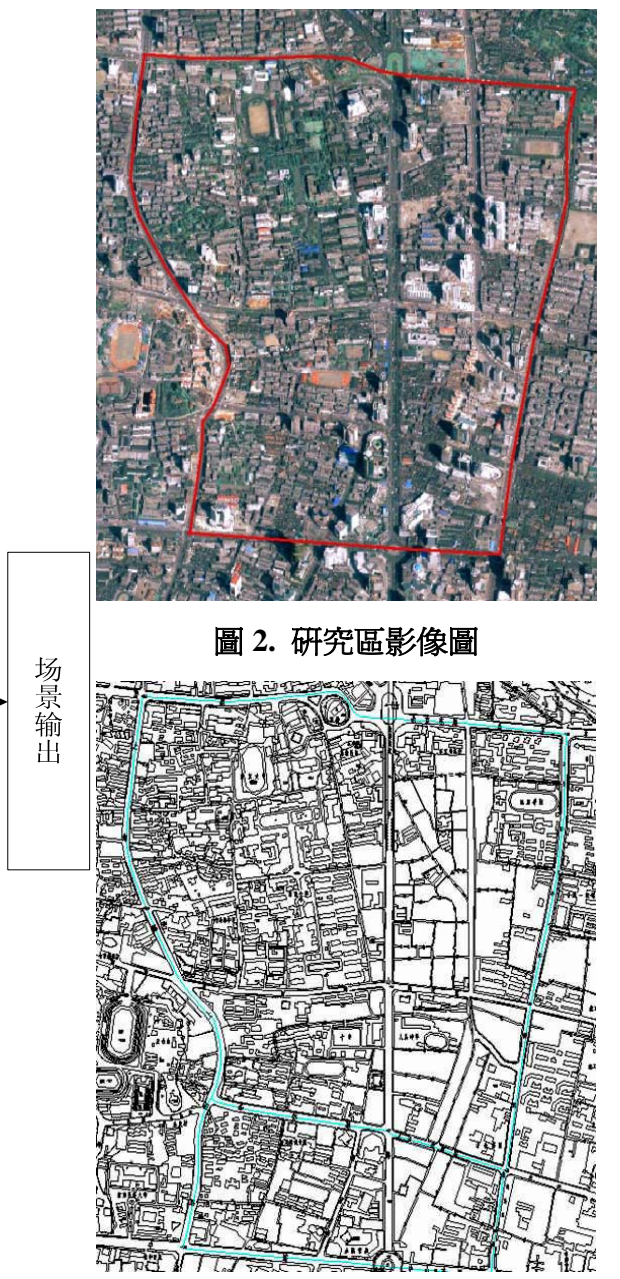

圖 3. 研究區 CAD 圖件 
資料[3]。

地形渲染通常使用數位高程模型(Digital Elevation Models，DEM)這一資料結構，DEM 資料能夠非 常近似地表現出地形的視覺特性。DEM 基礎資料採 用 1:500 南京地區的 CAD 圖件, 通過資料格式轉換和 編輯修整後將高程資料導出為文本格式, 將其組織為 不規則三角網生成演算法, 建立高程點的拓撲結構, 在此基礎上通過線性插值的方法生成該地區 DEM 規 則格網資料。

建築物模型通過半手工處理, 從現有的 CAD 圖 件中獲取建築物平面圖斑, 通過資料轉換到 ArcMap 支援的 Shape 格式, 利用 ArcMap 將圖件中不完整的 拓撲關係補充完整, 並得到研究區建築物的平面圖。 然後組織空間資料庫, 並根據原始圖件中的樓層高 度, 在資料庫中添加 Height 欄位。最後將資料導出, 通過編制程式導出為 DirectX 支援的*.X 檔, 生成便 於渲染操作的建築物模型。

此外還須提取該區域環境要素資料及空間分佈情 沉, 並對其作規整處理。由於本文重在對實現技術的 探討, 對研究區的環境要素資料採用類比的方式得 到。具體方法為: 在研究區相關區域設置若干個點狀 資料源(在具體應用中, 我們設定為電磁場源), 並設 置不同的能量擴散指數, 通過採樣生成離散資料。

\section{4. 三維地形渲染}

城市三維地形的視覺化渲染中往往需要處理龐大 的空間資料, 這對視覺化性能提出了較高的要求, 因 此, 能否採用高性能的渲染方法顯得十分重要。目 前, LOD (Level Of Details, 層次細節)技術[4]是一個 很好的思路, 利用 LOD 方法來控制地形表面格網的 精度, 即根據視點所處的方位來確定地形格網的解析 度, 通過修正格網的大小, 實現一定的精度覆蓋地形 表面, 適時的選擇相應的細節進行顯示, 這樣就避免 了因繪製那些意義相對不大的細節而造成的時間浪 費, 從而有效的協調了畫面連續性與模型解析度的關 係。

Texture Clipmap 的概念是由 C.Tanner 在 1998 年 提出的, 在此之前紋理映射中已經普遍使用一種建立 在 LOD 思想之上的 Mipmap 方法 [5], 這一概念的引 入對 Mipmap 的層構造進行裁剪, 獲得了紋理資料的 充分利用, 同時節省了存儲空間。基於目前不斷發展 的 GPU 渲染能力及處理速度, Losasso 等人[6]認為,
對於地形渲染演算法更應側重於讓地形的表面覆蓋塊 在螢幕上有統一的大小, 具有一定的精度, 並能夠適 應於 GPU 的圖形渲染管線。為此, 2004 年 Geometry Clipmap 演算法[7]被提出, 該演算法使用規則格網並 建立不同解析度的層來表達地形，在易於實現的基礎 上減小了 $\mathrm{CPU}$ 的計算開銷, 能保持足夠的繪製速 度, 同時有效地減小了構建不同解析度下紋理的圥餘 數據，簡化了計算複雜度。

考慮到 Geometry Clipmap 演算法的諸多優越性, 我們採用了如下的實現策略。對於一共有 $\mathrm{n}$ 層 clipmap 構成的地形, 定義第 0 層(LV0)為解析度最高 的層, 與原始地形的格網解析度一致, 定義第 $\mathrm{n}-1$ 層 (LVn-1)為解析度最低的層。各個層中格網的數量保 持一致, 且為 2 的幕次方 $(2 \mathrm{~m}, \mathrm{~m} \in \mathrm{N})$, 每個層中的 格網覆蓋範圍隨層數 $\mathrm{n}$ 的增大而增大, 並且 $\mathrm{Dn}+1=$ $\mathrm{Dn} \times 2$, 這裏 $\mathrm{D}$ 表示規則格網的邊長。在繪製的時 候, 將不同解析度下的層環繞在視點周圍, 就實現了 由遠及近的 LOD 繪製。在我們的實現中，為了保持 在不同層次之間總能嵌套環繞, 實際每層的格網數限 定為 4 的整數倍 $(4 \mathrm{~m}, \mathrm{~m} \in \mathrm{N})$ 。我們將地形的高度資 料存儲在格網的頂點中, 對於每一層來說, 格網的頂 點資料總數為 $2 \times(4 \mathrm{~m}+1),(\mathrm{m} \in \mathrm{N})$ 。

每個層 clipmap 中的資料根據視點的變化而更 新, 具體資料從原始的地形資料中讀取, 每一層根據 解析度的不同，使用不同的採樣步長。每一層的 clipmap 根據不同的用途，定義了兩個資料區域：活 動區域(Active Region), 和繪製區域(Render Region)。一般情況下, 活動區域就是該層 clipmap 覆蓋 的區域, 但是對於視點快速移動的情況下, 為了能夠 保持一定的繪製速度，不會去重新更新 clipmap，而 只是在當前 clipmap 基礎上, 再次裁剪以適應新的視 點位置; 繪製區域是最終進行繪製的區域, 由於解析 度低的層總是環繞在解析度高的層周圍, 低解析度層 在繪製的時候, 總是只繪製一個空心的“矩形環”, 即 繪製區域。

\section{5. 城市建築物的建模}

在城市建築物模型建立中,建築物除了表達其基 本平面位置及高度資訊外,還需表達其色彩紋理與幾 何外形特徵,這些幾何外形特徵往往體現三維物件特 別是建築物物件的獨特風格。1994 年 K. Graf 等人 [8] 
利用遙感影像和航拍影像進行紋理合成, 1998 年 H. Vanden[9]提出了通過單幀影像獲取 3D 模型的演算 法, 在 Frueh 和 Zakhor 等人開發的系統中[10]使用一 台車載的攝像機獲取建築物的紋理，N. Faust 等人[11] 提出即時的全球資料模型概念從而使得地理空間資料 容納到一個全球的座標體系內。

本研究中, 建築物的建模是在地形渲染的基礎上 進行疊加。每一棟建築物都有其自身的高度, 我們在 考虑疊加地形高程的基礎上, 繪製而成。建築物資料 同樣來自於 $1: 500$ 的 CAD 圖件，建築物資料經過資料 處理與修正, 構建出建築物平面結構圖（見圖 4), 轉換為 Shape 格式檔後, 組織空間數據庫屬性欄位, 並添加建築物高度資料, 最後導出到文字檔案中。在 繪製建築物的時候, 原理是將建築物在平面圖基礎上 按照高度拉伸，實現其 $3 \mathrm{D}$ 顯示。

我們首先通過編寫程式對建築物資料進行預處 理, 包括剔除不需要的面積極小的建築物, 或者高度 太低的建築物, 因為在繪製的時候發現, 這些建築物 基本上視覺效果不明顯。同時在程式中, 我們將文字 檔案中的資料手工恢復拓撲關係, 保存成 Direct3D 支 持的 Mesh 檔格式(.X)。全部建築物記錄 5014 個, 對 於錯誤的頂點資料和過於細節化的几餘節點進行自動 計算, 共剔除 734 個, 最終三角形頂點數量為 37852 個。利用 Direct3D 中由一組 COM 介面提供的繪製功 能(如 DrawSubset 方法)渲染 Mesh 資料, 並使用 Optimize Inplace 和 Optimize 方法優化重組 Mesh 的幾何資 訊, 使其渲染更為有效, 建築物建模效果顯示見圖 5。

\section{6. 電磁專題資料的疊加}

在電磁輻射環境仿真中, 目標是視覺化這些專題
資訊；而仿真模型方面，即電磁波傳播模型方面，已 經有很多相對較成熟的物理模型，這不是本文的研究 重點。本文的重點是怎麼用 GIS 技術來表現出其仿真 結果。在實驗研究中, 我們使用類比的產生的電磁場 資料作為體資料來源。

電磁場資料的視覺化涉及到磁場強度的視覺化和 電勢、磁勢數據的視覺化等, 前者為向量數據, 後 兩者為標量數據。向量資料的視覺化, 除了需要考 慮數值, 還要考慮空間方向的問題 [12]; 我們的工作 將主要針對電勢、磁勢等標量資料的視覺化。

由於視覺化過程中的資料無關性的特性，我們在 實際工作過程中，通過類比的方式來產生資料。對於 真實的電場強度, 完全可以通過物理的相關理論計 算求得。比如給出場源屬性的電荷分佈、電流分佈 等, 利用數值方法求解關於場強分佈的泊松方程, 就 可以得到一組最簡單的類比資料 [13]。我們在這裏使 用公式 $\Phi$ 來產生類比資料。並且假定靠近建築物核心 部分為高電勢，向外擴散數值逐步減小。

$$
H(u, v)=e^{-\left[\frac{\sqrt{u^{2}+v^{2}}}{D_{0}}\right]^{2}}(n \in N)
$$

對於電勢資料這類空間標量場，因其在空間成不 均与的非線性分佈, 因此我們需要能夠觀察相關他們 內部的數值分佈狀況, 此時用傳統的表面建模方法就 無法滿足應用。而體素渲染是一種具有空間實體資訊 的建模繪製手，我們認為其適合應用需求。

體素渲染方法是用體素的概念來描述空間實體, 為了能夠實現對空間內部的觀察, 體素渲染具有和表 面繪製方法不同的光線追蹤演算法。我們在此採用基 於硬體的加速演算法 [14]實現光線追蹤演算法, 利用

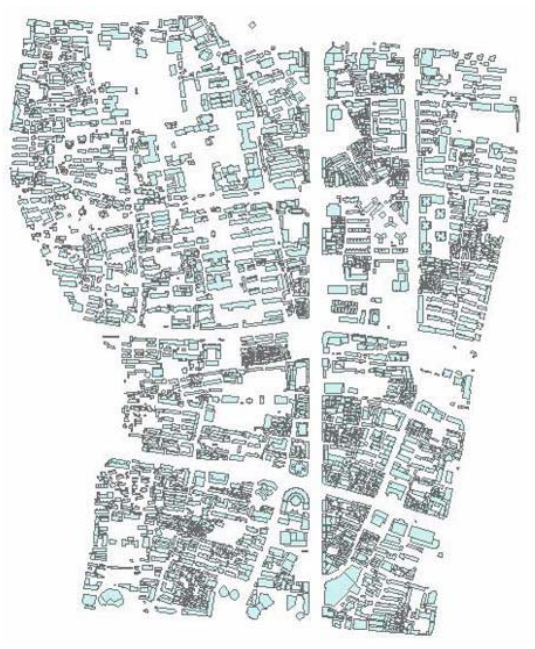

圖 4. 建築物平面結構圖

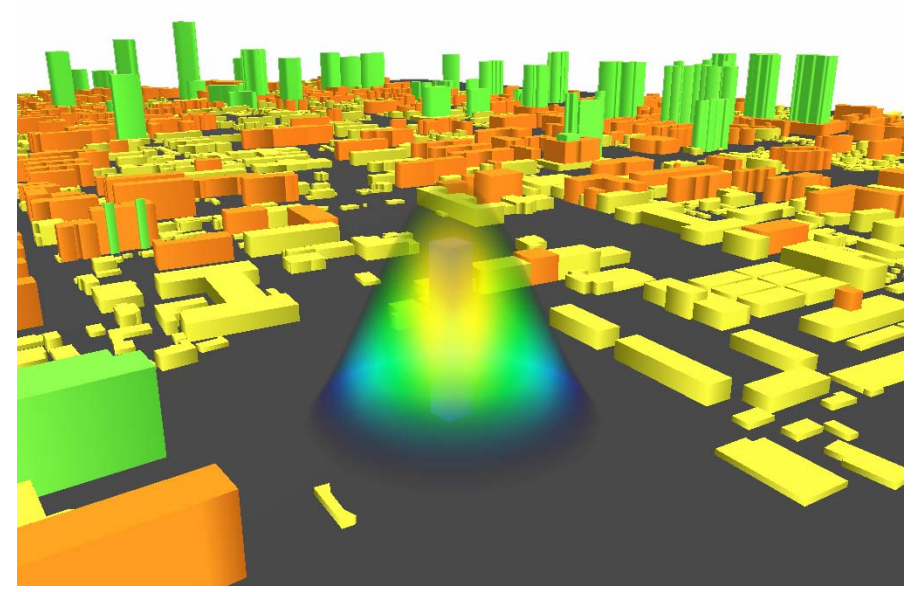

圖 5. 城市建築物建模及電磁專題顯示 
硬體加速可以使得原本由 CPU 進行的計算, 交由專 門設計的 GPU 完成, 大大提高了渲染效率, 在獲得 高品質場景輸出和更靈活的控制手段的時候, 同時降 低了 CPU 開銷。在光線追蹤下，我們採用從入射點 向出射點正向採樣的方法來計算, 並且通過參數來控 制採樣點之間的步長。採樣點的空間座標也就是對應 了這一點的紋理座標, 所以採樣資料可以從預先設置 的 3D 紋理中直接讀取獲得。當採樣點在出射點之外 時, 或者處於建築物表面時, 光線追蹤計算終止。將 得到的結果返回, 就是該片元點的顏色值, 最終經過 渲染流水線其他處理, 成為圖元的顏色值, 最終輸出 為螢幕上的一幀。在城市地形與建築物景觀的基礎 上, 疊加渲染電磁場資料, 其疊置渲染結果見圖 5 。 由於體素渲染演算法的資料結構不是通過表面模 型來描述空間物體, 而是使用體元, 因此易於對體資 料進行剖面觀察等操作。只需要在光線追蹤過程中, 設定不同的閾值, 使得當光線追蹤過程只在這些區域 內有效, 就可以實現剖面的效果。需要指出的是, 體 的空間資料本身並不具有顏色等資訊，可通過用戶交 互手段, 讓用戶動態調整顏色的映射方式進行預定 義, 對不同的資料進行或強化或弱化進而加以區分, 使得人眼可以直接關注熱點區域, 更快速的獲取資 訊, 避免被次要資訊干擾, 這正是視覺化的重要意義 所在。最常見的情況是將體資料的灰度值映射為 RGBA 四個維度, 這樣將低維資料映射到高維資料, 提供了對原始資料更多樣的表達。

\section{7. 結 語}

本文在 GIS 技術的支援下, 利用 Geometry Clipmap 演算法和 Direct3D 的 Mesh 介面分別實現了研究 區的地形渲染和建築物建模, 並將類比得到的電磁場 強度資料通過體繪製方法渲染疊加到所建立的具有三 維地形特徵的城市模型場景中, 基本實現了虛擬場景 中體資料(電磁場資料)的即時繪製。

研究證明, 我們採用上述技術路線, 進行基於 GIS 的電磁環境仿真, 是可行的, 具有應用參考價 值; 採用體繪製技術, 對於包括電磁輻射環境在內的 環境要素的視燢化, 是合理的, 有優勢的。但是, 由
於資料獲取等方面的原因, 本文的研究還存在不足, 離建立仿真系統還有距離，包括模型與 GIS 集成等方 面有待進一步研究。

\section{參考文獻 (References)}

[1] 高敒綱, 才慶安. 電磁環境對生態的危害及防護[J]. 基礎醫學與臨床, 2000, 20(1): 1-7.

[2] P. A. Longley 等編, 唐中實等譯. 地理資訊系統（上 卷) 一一原理與技術（第二版） [C]. 北京: 電子工業 出版社, 2004, 5-8.

[3] 王長清. 現代計算電磁學基礎[C]. 北京: 北京大學出 版社, 2005.

[4] H. Hoppe. Progressive meshes [C]. Proceedings of the SIGGRAPH, 1996, 99-108.

[5] L. Williams. Pyramidal Parametric. In Peter Tanner, editor, Computer Graphics (SIGGRAPH 83 Conference Proceedings), ACM SIGGRAPH, ISBN: 0-89791-109-1.July 1983, 17, 1-11.

[6] F. Losasso, H. Hoppe, S. Schaefer, and J. Warren. Smooth geometry images. Symposium on Geometry Processing, 2003, 138-145.

[7] F. Losasso and H. Hoppe, Geometry clipmaps: Terrain rendering using nested regular grids. ACM Trans, 2004, 23(3): 769-776.

[8] K. Graf, M. Suter, J. Hagger, and D. Nijesch. Computer graphics and remote sensing: A synthesis for environmental planning and civil engineering. Proceedings of EURGGRAPHICS, 1994, 13(3): 13-22.

[9] H. Vanden and A. Frank. 3D reconstruction from a single image using geometric constraints. PandRS, 1998, 53(6): 354-368.

[10] C. Frueh and A. Zakhor. 3D model generation for cities using aerial photographs and ground level laser scans. IEEE Computer Vision and Pattern Recognition, 2001, 2(2): 31-38.

[11] N. Faust, W. Ribarsky, T. Y. Jiang, and T. Wasilewski. Real- time global data model for the digital earth. International Conference on Discrete Global Grids, 2000.

[12] M. J. Silva, S. Zhang, C. Demiralp, and D. H. Laidlaw. Visualizing diffusion tensor volume differences. Proceedings of IEEE Visualization, 2001.

[13] 王長清. 現代計算電磁學基礎[C]. 北京: 北京大學出 版社, 2005.

[14] J. Kruger and R. Westermann. Acceleration techniques for GPU-based volume rendering. Proceedings of IEEE Visualization, 2003. 
